\title{
Effect of Processing Condition and Polishing Rate on Apparent Amylose Content of Some Sri Lankan Rice Varieties
}

\author{
H.D.K. Darandakumbura, B.D.R. Prasantha ${ }^{1 *}$ and D.G.N.G. Wijesinghe ${ }^{1}$ \\ Postgraduate Institute of Agriculture \\ University of Peradeniya \\ Peradeniya, Sri Lanka
}

\begin{abstract}
Rice ( Oryza sativa) is the staple food in Sri Lanka. Amylose content is the key determinant of cooking and eating qualities of rice. Therefore it is commonly used as an objective index for cooked rice texture. High amylose varieties tend to have low glycemic indices. This study investigated the apparent amylose content of raw and parboiled rice which were polished at $10 \%$ and $5 \%$ on weight basis in six Sri Lankan rice varieties. Determination of apparent amylose content was done according to AACC method 61-03. Five Bg varieties; 2 short grain (Bg 358, Bg 360), two medium grain (Bg 300, Bg 352) and one long grain (Bg 305) were used for the study together with the long grain rice variety At 405. The apparent amylose content of rice varieties $\mathrm{Bg} 300, \mathrm{Bg} 305, \mathrm{Bg} 352, \mathrm{Bg} 358, \mathrm{Bg} 360$ and At 405 under $10 \%$ polished raw were $29.3 \pm 0.4 \%, 32.5 \pm 1.3 \%, 32.8 \pm 0.75 \%, 26.1 \pm 0.8 \%$, $31.9 \pm 0.8 \%$ and $14.9 \pm 1.3 \%$, respectively. A significant difference $(p<0.05)$ was observed for apparent amylose content among the selected rice varieties. Bg 305, Bg 360 and Bg 352 had a significantly higher apparent amylose content than Bg 358, Bg 300 and At 405 under 10\% polished raw form. All the five Bg varieties tested in the study belong to high amylose rice while the variety At 405 is a low amylose type. Although there was a significant varietal difference in apparent amylose content of rice no clear difference was observed in apparent amylose content due to parboiling or polishing.
\end{abstract}

Key words: Apparent amylose content, parboilng, polishing rate, rice

\section{INTRODUCTION}

Rice (Oryza sativa) is the staple food in Sri Lanka. It contributes to nearly $50 \%$ of the energy and $40 \%$ of protein in the daily diet of its people (Sartaj and Suraweera, 2005). Rice sector contributes to $30 \%$ of the agricultural Gross Domestic Product (GDP) of Sri Lanka. Rice is grown under both irrigated and non-irrigated conditions (Mendis, 2009). The annual per capita consumption of rice in Sri Lanka has increased from $100 \mathrm{~kg}$ in 2000 to $108 \mathrm{~kg}$ in 2008, mainly due to increasing prices of wheat flour. In addition, a demand for physical purity as well as for better intrinsic quality in rice has also been increased (Kotagama and Kumara, 1996). Rice is mainly consumed as cooked grain kernels. Physicochemical properties of cooked rice are important for its edible quality. Rice grain quality has four constituents as milling quality, appearance quality, cooking quality and eating quality. Physicochemical properties such as the amylose content, gelatinization temperature and gel consistency have an effect on cooking and eating qualities (Zefu et al., 2003).

\footnotetext{
1 Department of Food Science and Technology, Faculty of Agriculture, University of Peradeniya, Sri Lanka Corresponding author: wijeng@yahoo.com
} 
Amylose content is the key determinant of the cooking and eating qualities of rice (Wickramasinghe and Noda, 2008). It is commonly used as an objective index for cooked rice texture (Delwiche et al., 1995). Low amylose levels are associated with cohesive, tender and glossy cooked rice while high amylose levels tend to absorb more water and expand more during cooking. Grains with high amylose contents tend to cook dry, fluffy and separate (Juliano, 1971). High amylose varieties tend to have low glycemic index values which are suitable for diabetic patients (Miller et al., 1992). This is mainly due to the less susceptibility of high amylose starches to hydrolysis by $\alpha$-amylase as it is a larger linear molecule and not branched as amylopectin (Pathiraje et al., 2010). In general high quality rice is considered to be soft and slightly moist when cooked. These qualities are provided by starches with intermediate amylose and moderate gelatinization temperatures (Wickramasinghe and Noda, 2008). The environmental conditions such as changes in the temperature and day length and also genotype-environment interactions affect the cooking and eating qualities of rice (Jianrong et al., 2005).

Amylose content of rice can be categorized as waxy (0-5\%), very low (5-12\%), low (12$20 \%$ ), intermediate (20-25\%) and high (25-33\%) (Juliano, 1971). Commercially rice is classified on the basis of its amylose content as either low ( $<20 \%$ amylose), medium (21$25 \%$ amylose) and high (26-33\% amylose) (Suwannaporn et al., 2007). It has been reported that parboiling would reduce the amylose content of rice (Ostegbayo et al., 2001) but the effect of polishing on its amylose content is not known. The objective of this study was to determine the amylose content in six popularly consumed Sri Lankan rice varieties under different processing conditions: raw and parboiled and different polishing rates: $10 \%$ (fully) and $5 \%$ (half) on weight basis.

\section{MATERIALS AND METHODS}

\section{Raw materials}

The short grain (Bg358, Bg360), medium grain (Bg 300, Bg 352) and long grain (Bg 305, At 405) rice varieties were obtained from Bathalagoda Rice Research Institute, Sri Lanka. Parboiling and polishing operations were done in the laboratories of the Faculty of Agriculture, University of Peradeniya, Sri Lanka. Parboiling was done by soaking paddy in water: short grains were soaked for 24 hours and long grains were soaked for 48 hours, followed by steaming and sun drying as described by Juliano (1971). The variety At 405 is a Basmati type rice, which is not commercially parboiled and hence it was not subjected to parboiling in this study.

\section{Sample preparation}

Both raw and parboiled rice from the five $\mathrm{Bg}$ varieties were polished at $10 \%$ (degree of polishing $100 \%$ ) and $5 \%$ (degree of polishing 50\%) on the basis of weight with the rice husker and polisher (PM 500, Japan) which has the capacity of adjusting the rate of polishing. After polishing methylene blue was used to stain the surface of rice to ascertain the effectiveness of polishing. In the case of variety At 405, only the.raw form of the rice was used for the study, following the commercial preparation method, and it was polished only at $10 \%$ rate.

Rice was ground (M-2, Kansas) and passed through a $0.5 \mathrm{~mm}$ sieve. The samples were then de-fatted by refluxing $95 \%$ ethanol for $16 \mathrm{~h}$ in a Soxhlet extractor. Triplicates of $100 \mathrm{mg}$ 
samples were weighed and transferred quantitatively to $100 \mathrm{ml}$ volumetric flasks, $1 \mathrm{ml}$ of 95\% ethanol was added carefully washing down any sample adhering to sides of tube. Then the tubes were vortexed thoroughly. Sodium hydroxide ( $9 \mathrm{ml}$ of $1 \mathrm{~N}$ solution) was added to each sample and kept at room temperature for $24 \mathrm{~h}$ without shaking. After dispersion, starch solutions were made into $100 \mathrm{ml}$ volume with distilled water and vortexed vigorously. One in to ten dilutions was then prepared for each solution. Three replicates were prepared for each variety under raw and parboiled conditions and the two polishing rates.

\section{Determination of amylose content}

Apparent amylose content was determined according to AACC (2000) method 61-03. Solutions (1g/liter) of potato amylose (Sigma-Aldrich, UK) and amylopectin (Himedia Laboratories, India) were prepared using $1 \mathrm{ml}$ of $95 \%$ ethanol following the procedure described above for the preparation of samples. They were used as stock solutions for preparing working solutions. Amylose/amylopectin mixtures for the standard curve were prepared as shown in table 1.

Standard curve was prepared using Amylose or amylopectin solutions. Amylose or amylopectin solutions were pipetted $(5 \mathrm{ml})$ into $100 \mathrm{ml}$ volumetric flasks, each containing about $50 \mathrm{ml}$ distilled water. Blank was prepared using $5.0 \mathrm{ml}, 0.09 \mathrm{~N}$ sodium hydroxide. Then $1.0 \mathrm{ml} 1 \mathrm{~N}$ acetic acid was added and mixed. Thereafter $2 \mathrm{ml}$ iodine solution was added and made up to $100 \mathrm{ml}$ with distilled water and mixed. Then they were allowed to stand for 20 minutes and color absorbance was red at $620 \mathrm{~nm}$ using the blank to zero the spectrophotometer (UV-1601, Japan). The absorbance was plotted at $620 \mathrm{~nm}$ against amylose concentration of working solutions for a standard curve. Aliquots $(5 \mathrm{ml})$ of alkaline dispersions of samples were pipetted into $100 \mathrm{ml}$ volumetric flasks, each containing about 50 $\mathrm{ml}$ of distilled water. Sodium hydroxide $(0.09 \mathrm{~N}, 50 \mathrm{ml})$ was used for the blank. Then the absorbances were measured three times per replicates at $620 \mathrm{~nm}$ as described above and plotted against the assigned amylose content and the mean amylase content was obtained for each replicate.

Table 1. Amylose and amylopectin ratios for the working solutions

\begin{tabular}{cccc}
\hline $\begin{array}{l}\text { Amylose in milled rice } \\
(\% \text { dry basis })\end{array}$ & \multicolumn{3}{c}{ Volume ratio of stock solution (ml/100 ml) } \\
\cline { 2 - 4 } & $\begin{array}{c}\text { Amylose } \\
(\mathbf{m l})\end{array}$ & $\begin{array}{c}\text { Amylopectin } \\
(\mathbf{m l})\end{array}$ & $\mathbf{0 . 0 9} \mathbf{~ N ~ N a O H}$ \\
\hline 0 & 0 & 7.0 & 3 \\
10 & 1.0 & 6.0 & 3 \\
20 & 2.0 & 5.0 & 3 \\
25 & 2.5 & 4.5 & 3 \\
30 & 3.0 & 4.0 & 3 \\
\hline
\end{tabular}

\section{Statistical analysis}

Data obtained from each variety under different processing conditions and polishing rates were fitted into a factorial $(5 \times 2 \times 2)$ completely randomized design (CRD) and subjected to analysis of variance (ANOVA). Mean separation was done using the Duncan's Multiple Range Test to determine the statistical differences among varieties at a significance level of 0.05. Statistical analysis was carried out using SAS (1990) software package. 


\section{RESULTS}

As the highest order interaction was significant, man separations were done separately.

\section{Effect of variety on apparent amylose content of rice}

A significant difference $(\mathrm{p}<0.05)$ was observed for apparent amylose content among the selected rice varieties. $\mathrm{Bg} 305, \mathrm{Bg} 360$ and $\mathrm{Bg} 352$ had a significantly higher apparent amylose content than Bg 358, Bg 300 and At 405 under 10\% polished raw form (Table 2). According to the classification of rice based on amylose content, At 405 is a low amylose type and the other five varieties belong to high amylose type. When short, medium and long grain categories were compared a clear difference in the amyloase content was not observed among them.

Table 2. Apparent amylose content of rice varieties (raw) under $10 \%$ polishing rate

\begin{tabular}{lc}
\hline Variety & Apparent amylose content $(\%)$ \\
\hline Bg 305 & $32.5 \pm 1.3^{\mathrm{a}^{*}}$ \\
Bg 358 & $26.0 \pm 0.8^{\mathrm{c}}$ \\
$\operatorname{Bg} 360$ & $31.9 \pm 0.8^{\mathrm{a}}$ \\
$\operatorname{Bg} 300$ & $29.3 \pm 0.4^{\mathrm{b}}$ \\
Bg 352 & $32.8 \pm 0.7^{\mathrm{a}}$ \\
At 405 & $14.9 \pm 1.3^{\mathrm{d}}$ \\
\hline
\end{tabular}

* Mean $\pm \mathrm{SD}(\mathrm{n}=3)$. Means bearing the same simple letter are not significantly different at $\mathrm{p}=0.05$

\section{Effect of polishing rate on apparent amylose content of rice}

As shown in table 3 there is no significant difference $(\mathrm{p}>0.05)$ in apparent amylose content in raw form of $\mathrm{Bg} 305, \mathrm{Bg} 358, \mathrm{Bg} 352$ and $\mathrm{Bg} 360$ varieties under 10\% polished or 5\% polished conditions. When consider the parboiled varieties, there is no significant difference on apparent amylose content between $10 \%$ polished and 5\% polished form of five $\mathrm{Bg}$ varieties (Table 4).

Table 3. Apparent amylose content of rice varieties (raw) under different polishing rates

\begin{tabular}{lcc}
\hline Rice variety & \multicolumn{2}{c}{ Apparent amylose content (\%) } \\
\cline { 2 - 3 } & $\mathbf{5 \%}$ polished & $\mathbf{1 0 \%}$ polished \\
\hline Bg 305 & $31.9 \pm 1.8^{\mathrm{a}^{*}}$ & $32.4 \pm 1.3^{\mathrm{a}}$ \\
Bg 358 & $26.2 \pm 1.3^{\mathrm{a}}$ & $26.0 \pm 0.8^{\mathrm{a}}$ \\
Bg 360 & $32.1 \pm 0.4^{\mathrm{a}}$ & $31.9 \pm 0.8^{\mathrm{a}}$ \\
Bg 300 & $30.3 \pm 0.5^{\mathrm{a}}$ & $29.9 \pm 0.4^{\mathrm{a}}$ \\
Bg 352 & $31.4 \pm 1.6^{\mathrm{a}}$ & $32.8 \pm 0.7^{\mathrm{a}}$ \\
\hline
\end{tabular}

* Mean $\pm \mathrm{SD}(\mathrm{n}=3)$. Means bearing the same simple letter in a raw are not significantly different at $\mathrm{p}=0.05$ 
Table 4. Apparent amylose content of rice varieties (parboiled) under different polishing rates

\begin{tabular}{lcc}
\hline Rice variety & \multicolumn{2}{c}{ Apparent amylose content $(\%)$} \\
\cline { 2 - 3 } & $\mathbf{5 \%}$ polished & $\mathbf{1 0 \%}$ polished \\
\hline Bg 305 & $32.0 \pm 1.7^{\mathrm{a}^{*}}$ & $31.7 \pm 1.0^{\mathrm{a}}$ \\
$\mathrm{Bg} 358$ & $26.7 \pm 2.3^{\mathrm{a}}$ & $26.6 \pm 0.8^{\mathrm{a}}$ \\
$\mathrm{Bg} 360$ & $33.2 \pm 0.7^{\mathrm{a}}$ & $30.9 \pm 1.6^{\mathrm{a}}$ \\
$\operatorname{Bg} 300$ & $30.6 \pm 2.2^{\mathrm{a}}$ & $29.2 \pm 1.7^{\mathrm{a}}$ \\
Bg 352 & $34.0 \pm 1.5^{\mathrm{a}}$ & $33.8 \pm 0.7^{\mathrm{a}}$ \\
\hline
\end{tabular}

$*$ Mean $\pm \mathrm{SD}(\mathrm{n}=3)$. Means bearing the same simple letter in a raw are not significantly different at $\mathrm{p}=0.05$

\section{Effect of parboiling on apparent amylose content of rice}

Referring to the table 5, there is no significant difference $(\mathrm{p}>0.05)$ in apparent amylose content in rice varieties between $5 \%$ polished raw and 5\% polishedd parboiled suggesting that parboiling has no effect on apparent amylase content when 5\% polished. The same pattern is observed between $10 \%$ polished raw and $10 \%$ polished parboiled rice varieties (Table 6)

Table 5. Apparent amylose content of rice varieties (raw andparboiled) under 5\% polishing rate

\begin{tabular}{lcc}
\hline Rice variety & \multicolumn{2}{c}{ Apparent amylose content (\%) } \\
\cline { 2 - 3 } & Raw & Parboiled \\
\hline Bg 305 & $31.9 \pm 1.8^{\mathrm{a}^{*}}$ & $32.0 \pm 1.7^{\mathrm{a}}$ \\
$\mathrm{Bg} 358$ & $26.2 \pm 1.3^{\mathrm{a}}$ & $26.7 \pm 2.3^{\mathrm{a}}$ \\
$\mathrm{Bg} 360$ & $32.1 \pm 0.4^{\mathrm{a}}$ & $33.2 \pm 0.7^{\mathrm{a}}$ \\
$\mathrm{Bg} 300$ & $30.3 \pm 0.5^{\mathrm{a}}$ & $30.6 \pm 2.2^{\mathrm{a}}$ \\
Bg 352 & $31.4 \pm 1.6^{\mathrm{a}}$ & $34.0 \pm 1.5^{\mathrm{a}}$ \\
\hline
\end{tabular}

* Mean $\pm \mathrm{SD}(\mathrm{n}=3)$. Means bearing the same simple letter in a raw are not significantly different at $\mathrm{p}=0.05$

Table 6. Apparent amylose content of rice varieties (raw andparboiled) under $10 \%$ polishing rate

\begin{tabular}{lcc}
\hline Rice variety & \multicolumn{2}{c}{ Apparent amylose content (\%) } \\
\cline { 2 - 3 } & Raw & Parboiled \\
\hline Bg 305 & $32.4 \pm 1.3^{\mathrm{a}^{*}}$ & $31.7 \pm 1.0^{\mathrm{a}}$ \\
Bg 358 & $26.0 \pm 0.8^{\mathrm{a}}$ & $26.6 \pm 0.8^{\mathrm{a}}$ \\
Bg 360 & $31.9 \pm 0.8^{\mathrm{a}}$ & $30.9 \pm 1.6^{\mathrm{a}}$ \\
Bg 300 & $29.9 \pm 0.4^{\mathrm{a}}$ & $29.2 \pm 1.7^{\mathrm{a}}$ \\
Bg 352 & $32.8 \pm 0.7^{\mathrm{a}}$ & $33.8 \pm 0.7^{\mathrm{a}}$ \\
\hline
\end{tabular}

* Mean $\pm \mathrm{SD}(\mathrm{n}=3)$. Means bearing the same simple letter in a raw are not significantly different at $\mathrm{p}=0.05$ 


\section{DISCUSSION}

Amylose content is considered the single most important factor for predicting the behavior of rice cooking and processing (Zhou, 2002). Amylose content is directly related to water absorption, volume expansion, fluffiness, and separatability of cooked grains. The consumer's concern is to get rice of better qualities (cooking and eating), that is largely dependent on the physico-chemical properties of starch which make up $90 \%$ of milled rice (Bhattacharjee et al., 2002).

The apparent amylose content of a rice variety can be varied due to the differences in the methodology adopted. Wickramasinghe and Noda (2008) have reported similar values for the amylose content of some of the varieties reported in this study. Following the blue value method, they estimated the apparent amylose content of varieties $\mathrm{Bg} 358, \mathrm{Bg} 352, \mathrm{Bg} 300$ and At 405 to be $27.3 \%, 32.6 \%, 33.7 \%$ and $16.0 \%$, respectively. According to Fari et al. (2011) the amylose content of the varieties Bg 352, Bg 300 and At 405 were 28.9\%, 26.8\% and $18.7 \%$, respectively. According to Juliano (1984) the amylose content based on blue value tends to be higher. Pillaiyar and Mohandoss (1981) reported that soluble amylose (in gruel) content was negatively correlated with the temperature of parboiling process. Similarly, Archana et al. (2007) have also reported that significant decrease in amylose content, hot water soluble amylose content and starch iodine blue value of high temperature $\left(>50{ }^{\circ} \mathrm{C}\right)$ cured and steamed Basmati and non-Basmati rice varieties compared to control samples. Ostegbayo et al. (2001) reported that the parboiling tends to reduce the amylose content of rice. However this study did not show any significant difference of apparent amylose content between raw and parboiled varieties of rice.

It is reported that endosperm starch amylose content is influenced by ambient temperature and that high ambient temperatures decrease the amylose content while the cool temperatures during grain development increase the amylose content (Juliano, 2003). Other than the environment temperature, genetics play a major role in the amylose content of rice. The level of waxy gene protein increases in lower temperatures leading to high amylose content in mature seeds. Therefore amylose content can vary within the same year and site of cultivation, even for the same cultivar (Suzuki et al., 2003). Apart from that minor genes and the environment also have an influence on amylose content of rice (Chen et al., 2007).

\section{CONCLUSIONS}

The apparent amylose content of rice varieties $\mathrm{Bg} 300, \mathrm{Bg} 305, \mathrm{Bg} 352, \mathrm{Bg} 358, \mathrm{Bg} 360$ and At 405 under $10 \%$ polished raw were $29.3 \%, 32.5 \%, 32.8 \%, 26.1 \%, 31.9 \%$ and $14.9 \%$, respectively. All the five $\mathrm{Bg}$ varieties tested in the study belong to high amylose rice while the variety At 405 is a low amylose type. There is no significant difference in the apparent amylose content with the polishing rate or parboiling operation.

\section{ACKNOWLEDGEMENT}

The Council for Agricultural Research Policy (CARP), Sri Lanka is gratefully acknowledged for providing the financial support and Bathalagoda Rice Research Institute, Sri Lanka and the departments of Food Science and Technology and Agricultural Engineering of Faculty of Agriculture, University of Peradeniya are gratefully acknowledged for providing rice samples and technical support respectively. 


\section{REFERENCES}

AACC (2000). Approved Methods of the American Society of Cereal Chemists. American Association of Cereal Chemistry. Inc. St. Paul, Minnesota, USA.

Archana, Singh, G. and Pandey, J. P. (2007). Effect of accelerated characteristics of 'Basmati' and non-'Basmati' rice. Journal of Food Science and Technology. 44, 443-445.

Bhattacharjee, P., Singhal, R.S. and Kulkarni, P.K. (2002) Basmati rice: a review. International Journal of food Science and Technology. 37, 1-12.

Chen, M., Bergman, C., Pinson, S., and Fjellstrom, R. (2007). Waxy gene haplotypes: Associations with apparent amylose content and the effect buthe environment in an international rice germplasm collection. Journal of Cereal Science. 47, 536-545.

Delwiche, S. R., Bean, M. M., Miller, R. E., Webb, B. D. and Williams, P. C. (1995). Apparent amylose content of milled rice by near infrared reflectance spectrophotometry. Journal of Cereal Chemistry. 72, 182-187.

Fari, M. J. M., Rajapaksa, D. and Ranaweera, K. K. D. S. (2011). Quality characteristics of noodles made from selected varieties of Sri Lankan rice with different physicochemical characteristics. Journal of National Science Foundation, Sri Lanka. 39, 53-60.

Jianrong, L., Chunhui, S., Mingguo, W. and Jianguo, W. (2005). Analysis of genetic effects for cooking quality traits of japonicarice across environments. Journal of Plant Science. 168, 1501-1506.

Juliano, B.O. (1971). A simplified assay for milled rice amylose. Journal of Cereal Science Today. 16, 334-340

Juliano, B.O. (1984). Rice starch: production, properties and uses. In Starch : Chemistry and Technology 2nd ed.

Juliano, B. O. (2003). Rice Chemistry and Quality. Island Publishing House, Manila. pp 117.

Kotagama, H. B. and Kumara, W. A. K. J. (1996). A hedonic price analysis of consumer preference on rice quality characteristics. Sri Lankan Journal of Agricultural Science. 33, 5973.

Mendis, A. (2009). Grain Report. USDA Foreign Agricultural Service. Global Agricultural Information Network. http://gain.fas.usda.gov/Pages/Default.aspx

Miller, J. B., Pang, E. and Bramall, L. (1992). Rice: a high or low glycemic index food? The American Journal of linical Nutrition. 76, 281-285.

Ostegbaya, B. O., Osamuel, F. and Fashakin, J. B. (2001). Effct of parboiling of physicochemical qualities of two local rice varieties in Nigeria. Journal of Food Technology in Africa. 6, 130-132. 
Pathiraje, P.M.H.D., Madhujith, W.M.T., Chendrasekara, A. and Nissanka, S. P. (2010). Effect of rice variety and parboiling on in vivo glycemic response Journal of Tropical Agricultural Research. 22, 26-33.

Pillaiyar, P. and Mohandoss, R. (1981). Cooking qualities of parboiled rices produces at low and high temperatures. Journal of the Science of Food and Agriculture. 32, 475-480.

Sartaj, I. Z. and Suraweera, S. A. E. R (2005). Comparison of different parboiling methods on the quality characteristics of rice. Annals of the Sri Lankan Department of Agriculture. 7, 245-252.

SAS Institute (1990) SAS language and procedures, version 6.1st edition. SAS Institute, Cary, NC.

Suwannaporn, P., Pitiphunpong, S. and Champangern, S. (2007). Classification of rice amylase content by discriminant analysis of physicochemical properties. Journal of Starch. 59, 61-67.

Suzuki, Y., Sano, Y., Ishikawa, T., Sasaki, T., Matsukura, U. and Hirano, H. (2003). Starch characteristics of the rice mutant $d u$ 2-2 Taichung 65 highly affected by environmental temperatures during seed development. Journal of Cereal Chemistry. 80, 184-187.

Whistler, R. L., BeMiller, J. N. and Paschall, E. F. (Eds.) (Academic Press, Inc., Orlando) pp. 507-524.

Wickramasinghe, H. A. M. and Noda, T. (2008). Physico chemical properties of starches from Sri Lankan rice varieties. Food Science and Technology Research. 14, 49-54.

Zefu, L., Jianmin, W., Jiafa, X. and Masahiro, Y. (2003). Mapping of quantitative trait laci controlling physico chemical properties of rice grains (Oryza sativa L.) Journal of Breeding Science. 53, 209-215.

Zhou, Z., Robards, K., Helliwell, S. \& Blanchard, C. (2002) Ageing of stored rice: changes in chemical and physical attributes. Journal of Cereal Science. 35, 65-78. 